\title{
A comparison of suicide rates between older adults in Ireland and the UK: 1975-2005
}

\author{
L. Power · J. Brophy
}

Published online: 14 November 2008

(C) Royal Academy of Medicine in Ireland 2008

\section{Erratum to: Ir J Med Sci}

\section{DOI 10.1007/s11845-008-0183-6}

Due to a transposition error in the above article the raw numbers for the suicide rate in Ireland were inadvertently graphed against the rate per 100,000 in the United Kingdom. Therefore the tables and graphs shown are incorrect and the Irish trend has been replotted (Fig. 1). As can be seen from the amended figure, the greatest proportion of the rise occurred between 1975 and 2005 and declines thereafter but the further trend is not yet apparent. Perhaps the increase has peaked and the UK and Irish trends will continue to converge. The authors acknowledge and regret the error and have sought to identify it and correct it at the first opportunity.

Table 1

\begin{tabular}{|c|c|c|c|c|c|c|c|c|c|c|c|}
\hline \multicolumn{6}{|c|}{ Ireland } & \multicolumn{6}{|l|}{ UK } \\
\hline \multicolumn{2}{|c|}{ Males $65+$} & \multicolumn{2}{|c|}{ Females $65+$} & \multicolumn{2}{|c|}{ Both sexes $65+$} & \multicolumn{2}{|c|}{ Males $65+$} & \multicolumn{2}{|c|}{ Females $65+$} & \multicolumn{2}{|c|}{ Both sexes $65+$} \\
\hline 1975 & 6.4 & 1975 & 2.6 & 1975 & 4.3 & 1975 & 22 & 1975 & 14.9 & 1975 & 17.7 \\
\hline 1980 & 9.8 & 1980 & 4.5 & 1980 & 6.9 & 1980 & 24.8 & 1980 & 16.5 & 1980 & 19.8 \\
\hline 1985 & 16 & 1985 & 5.1 & 1985 & 9.9 & 1985 & 24.6 & 1985 & 15.3 & 1985 & 19 \\
\hline 1990 & 16.7 & 1990 & 4.9 & 1990 & 10 & 1990 & 21.7 & 1990 & 9.6 & 1990 & 14.5 \\
\hline 1995 & 22.1 & 1995 & 2.5 & 1995 & 10.9 & 1995 & 16.8 & 1995 & 6.9 & 1995 & 11 \\
\hline 2000 & 12 & 2000 & 5.8 & 2000 & 8.5 & 2000 & 15.8 & 2000 & 6 & 2000 & 10.1 \\
\hline 2005 & 10.4 & 2005 & 4.3 & 2005 & 7 & 2005 & 13.6 & 2005 & 4.8 & 2005 & 8.6 \\
\hline
\end{tabular}

The online version of the original article can be found under doi:10.1007/s11845-008-0183-6.

L. Power $(\bowtie) \cdot$ J. Brophy

Newcastle Hospital, Greystones, Co.Wicklow, Ireland

e-mail: Lorna_power@hotmail.com

J. Brophy

e-mail: jjbrophy@clubi.ie 
Fig. 1

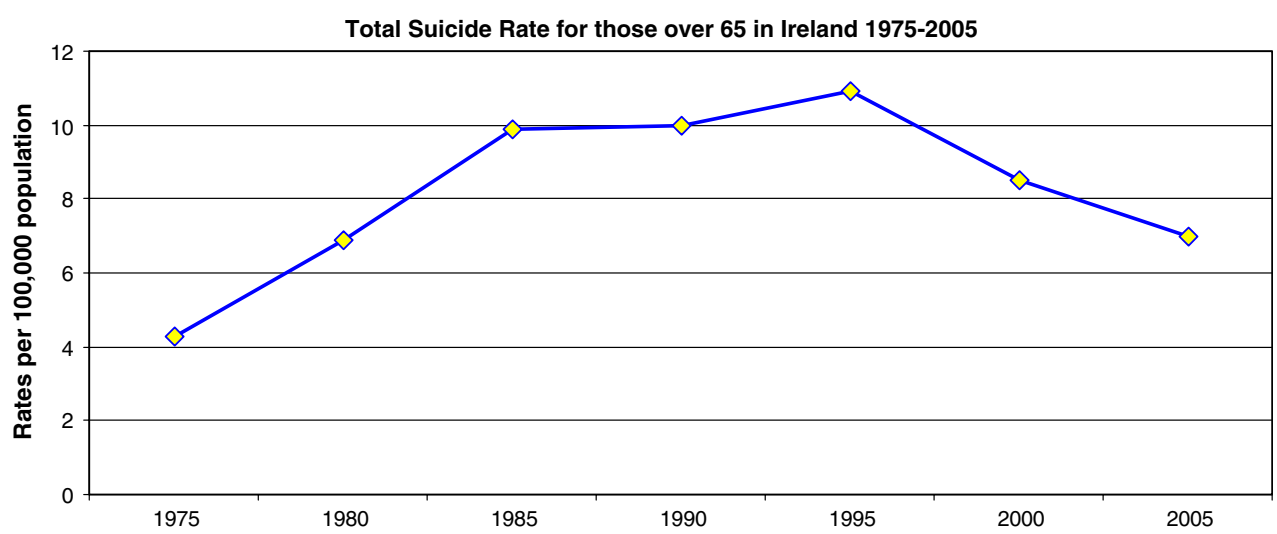

